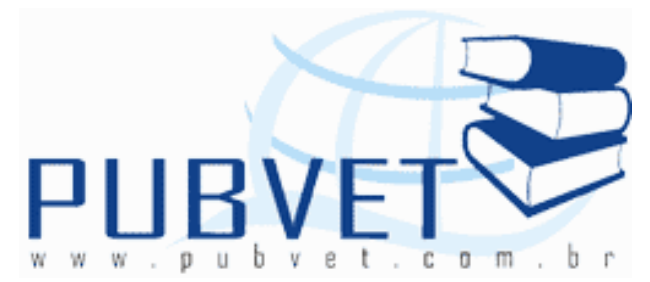

PUBVET, Publicações em Medicina Veterinária e Zootecnia.

\title{
Avaliação de dois diluentes de refrigeração e o efeito da presença do plasma seminal sobre a viabilidade do sêmen equino refrigerado
}

\author{
Rossane Pereira da Silva²; Karen Martins Leão ${ }^{3}$; Elen de Paula Matias \\ Moutinho²; Natalia do Carmo Silva²; Moraima Castro Rodrigues ${ }^{2}$; Marco \\ Antônio Pereira da Silva ${ }^{4}$
}

${ }^{1}$ Trabalho apresentado pela primeira autora como parte das exigências para conclusão do curso de bacharelado de Zootecnia do Instituto Federal de Educação, Ciência e Tecnologia Goiano - Campus Rio Verde

${ }^{2}$ Zootecnista pelo Instituto Federal de Educação, Ciência e Tecnologia Goiano Campus Rio Verde;

${ }^{3}$ Médica Veterinária, Profa. Dra. do Instituto Federal de Educação, Ciência e Tecnologia Goiano - Campus Rio Verde;

${ }^{4}$ Zootecnista, Prof. Dr. do Instituto Federal de Educação, Ciência e Tecnologia Goiano - Campus Rio Verde, e-mail: marcotonyrv@yahoo.com.br

\section{Resumo}

A tecnologia de sêmen equino refrigerado é estudada com intuito de manter seu potencial fertilizante por vários dias, quanto mais tempo o potencial fertilizante do sêmen refrigerado for estendido, mais fácil será a utilização do sêmen refrigerado. O objetivo do trabalho foi avaliar a eficácia de dois diluentes comerciais de refrigeração, Botu-Sêmen ${ }^{\circledR}$ e Equimix ${ }^{\circledR}$, bem como o efeito da presença do plasma seminal sobre a viabilidade do sêmen equino 
refrigerado. Utilizaram-se vinte e cinco ejaculados para refrigeração em seis protocolos: PI - Não centrifugado, diluído na proporção 2 (diluente): 1 (sêmen) com Botu-Sêmen ${ }^{\circledR}$. PII - Centrifugado e ressuspendido apenas com Botu-Sêmen $^{\circledR}$. PIII - Centrifugado e ressuspendido com Botu-Sêmen ${ }^{\circledR}$ e plasma seminal. PIV - Não centrifugado, diluído na proporção 2:1 com Equimix ${ }^{\circledR}$. PV Centrifugado e ressuspendido apenas com Equimix ${ }^{\circledR}$. PVI - Centrifugado e ressuspendido com Equimix ${ }^{\circledR}$ e plasma seminal. Avaliou-se integridade de membrana plasmática (\%) após 24 (T24) horas de refrigeração e motilidade total (\%), motilidade progressiva (\%) e vigor ( 0 a 5 ) logo após o preparo das amostras (T0) e após 24 (T24), 48 (T48), 72 (T72) horas de refrigeração. As amostras de sêmen foram armazenadas em geladeira a $5^{\circ} \mathrm{C}$. Foi utilizada análise de variância seguida do Teste de Tukey a 5\% para comparação das médias. Concluiu-se que não houve efeito dos diluentes testados e da presença do plasma seminal sobre os parâmetros avaliados do sêmen equino refrigerado até 72 horas de refrigeração a $5^{\circ} \mathrm{C}$.

Palavras-chave: cavalo, reprodução, inseminação artificial, viabilidade espermática.

\title{
Evaluation of two diluents of refrigeration and the effect of the presence of the seminal plasma on the viability of cooled equine semen
}

\begin{abstract}
The objective of the work was evaluate the effectiveness of two commercial diluents of refrigeration, Botu-Semen ${ }^{\circledR}$ and Equimix ${ }^{\circledR}$, and the effect of the presence of the seminal plasma on the viability of the cooled equine semen. Was used twenty five ejaculates for refrigeration in six protocols. Integrity of plasmatic membrane (\%) was evaluated after 24 (T24) hours of refrigeration and total motility (\%), progressive motility (\%) and vigor (0 the 5 ) soon after the preparation of samples (T0) and after 24 (T24), 48 (T48), 72 (T72) hours
\end{abstract}


SILVA, R.P. et al. Avaliação de dois diluentes de refrigeração e o efeito da presença do plasma seminal sobre a viabilidade do sêmen equino refrigerado. PUBVET, Londrina, V. 5, N. 20, Ed. 167, Art. 1126, 2011.

of refrigeration. The semen samples were stored in refrigerator $5^{\circ} \mathrm{C}$. Concluded that not have effect of the diluents tested and the presence of the seminal plasma on the parameters evaluated of the cooled equine semen up to 72 hours of refrigeration $5^{\circ} \mathrm{C}$.

Keywords: horse, reproduction, artificial insemination, spermatic viability.

\section{INTRODUÇÃO}

A equideocultura brasileira e mundial está em plena expansão devido principalmente a importância dada atualmente ao cavalo na prática de esportes, na lida no campo, na saúde humana (equoterapia), não podendo esquecer o importante papel destes animais no lazer, equitação, cavalgadas, entre outros.

A inseminação artificial (IA) é o ato de depositar mecanicamente o sêmen no trato reprodutivo da fêmea, em momento adequado, ocorrendo a partir daí, a fecundação do óvulo, dispensando assim a presença da fêmea e do macho no mesmo local no ato da deposição do sêmen no trato genital da fêmea.

A utilização da IA, possibilita a utilização de indivíduos geneticamente e zootecnicamente superiores, com custos de produção significativamente inferiores, o que permite um ganho genético consideravelmente rápido, proporcionando melhor aproveitamento do reprodutor e possibilitando a utilização de reprodutores que se encontram distantes, até porque se realizada de forma adequada, os resultados de fertilidade são similares aos da monta natural (MN).

Pesquisar a tecnologia de refrigeração de sêmen equino é necessário, pela vantagem de se manter o potencial fertilizante do sêmen por vários dias, quanto mais tempo o potencial fertilizante do sêmen refrigerado for estendido, maior será a aplicabilidade do sêmen refrigerado transportado.

Um aspecto importante no que diz respeito à possibilidade de se transportar o sêmen, é evitar problemas como estresse do transporte da égua 
até o garanhão, o que pode causar danos no desempenho destes animais em suas provas, que são as principais funções destes animais no mundo esportivo, evita também os riscos de transportar éguas com potro ao pé, há a diminuição de custos inerentes ao transporte destes animais e hospedagem em haras, além de ser uma forma prática e ágil de difundir materiais genéticos de alto potencial e evitar propagação de doenças sexualmente transmissíveis.

Vários são os pontos a serem observados na refrigeração de sêmen equino, uma vez que há elevadas variações nas taxas de fertilidade após a IA. Os fatores que podem afetar essas taxas incluem a fertilidade intrínseca do garanhão e da égua, a composição do diluente, a curva de refrigeração, a presença ou não do plasma seminal, a temperatura de armazenamento, a dose inseminante utilizada, o momento da inseminação, entre outros (PICKETT, 1995).

Durante a refrigeração, altas concentrações de plasma seminal são deletérias aos espermatozóides (BRINSKO et al., 2000). Uma alternativa para reduzir a concentração de plasma seminal é a centrifugação do sêmen e ressuspensão do mesmo apenas com meio diluente. Entretanto, segundo JASKO et al. (1992) são necessários aproximadamente 5\% de plasma seminal para manter a motilidade do sêmen refrigerado equino.

Levando em conta todos esses pontos a serem observados na refrigeração de sêmen equino, o objetivo do presente trabalho foi avaliar a eficácia de dois diluentes comerciais de refrigeração, Botu-Sêmen ${ }^{\circledR}$ (Biotech, Botucatu-SP) e Equimix ${ }^{\circledR}$ (Nutricell, Campinas-SP), bem como avaliar o efeito da presença do plasma seminal sobre a viabilidade do sêmen equino refrigerado.

\section{REVISÃO DE BIBLIOGRAFIA}

\subsection{Sêmen Equino Refrigerado}

O Brasil possui o quarto maior rebanho mundial de equinos ficando atrás somente dos Estados Unidos, China e México, montante este que propicia uma 
SILVA, R.P. et al. Avaliação de dois diluentes de refrigeração e o efeito da presença do plasma seminal sobre a viabilidade do sêmen equino refrigerado. PUBVET, Londrina, V. 5, N. 20, Ed. 167, Art. 1126, 2011.

movimentação de $R \$ 7,5$ bilhões por ano, gerando 3,2 milhões de empregos diretos e indiretos, números que demonstram a importância da atividade no país. A atividade está em franca ascensão visto que a receita com as exportações brasileiras de cavalos cresceu 769\% entre 1996 e 2005 (JUNIOR, 2004). Desta forma a "indústria do cavalo" vem se destacando e assumindo importante papel na economia nacional. Frente a este cenário, os ganhos genéticos alcançados através da inseminação artificial (IA) são indispensáveis para que haja expansão no plantel com boa genética.

Segundo NUNES (2006), o Brasil é o segundo país no mundo que mais utiliza IA com sêmen equino refrigerado. A utilização da IA com sêmen equino refrigerado é permitida pela maioria das associações de raças, possibilitando assim ampliar o uso de garanhões geneticamente superiores, fato que tem maximizado o interesse dos criadores por esta biotécnica da reprodução.

A IA com sêmen equino refrigerado tem se difundido bastante entre os haras, por possibilitar a utilização garanhões que estão alojados em centrais, o que facilita os acasalamentos (NUNES et al., 2006). As biotecnologias da reprodução contribuem bastante no progresso da reprodução de diversas espécies, principalmente se tratando de animais de produção. Muitas pesquisas têm sido realizadas no intuito de desenvolver, aprimorar e difundir as biotecnologias da reprodução, dentre as quais a mais utilizada é a IA por se mostrar a mais economicamente viável e de fácil implantação, além de ser base para realização das demais biotécnicas, como a transferência de embriões (PIMENTEL \& CARNEIRO, 2008). O desenvolvimento de técnicas adequadas para a preservação e armazenamento de sêmen é um dos passos de maior importância neste avanço, uma vez que esta possibilita um maior aproveitamento de animais de alto potencial genético, através da IA (MELO, 2005).

Apesar dos diversos estudos desenvolvidos, o uso do sêmen congelado de garanhões em programas de inseminação artificial, não apresenta resultados satisfatórios de fertilidade. Segundo VIDAMENT et al. (1997), a proporção de garanhões que não possuem resposta satisfatória ao 
congelamento é alta, em torno de 20 a 40\%. Certamente, esse é o principal motivo, de o sêmen refrigerado ser mais utilizado na indústria equina do que o sêmen congelado, já que se utilizado dentro de um período de 24 horas, o sêmen equino refrigerado apresenta índices de fertilidade bastante semelhante ao sêmen fresco (MELO, 2005).

De qualquer forma a utilização de sêmen refrigerado se torna interessante quando o sêmen é capaz de manter sua capacidade fertilizante por alguns dias. Quanto mais tempo o potencial fertilizante do sêmen refrigerado for estendido, mais viável será uso do sêmen transportado (BATELLIER et al., 2001). Infelizmente, a fertilidade na IA com sêmen refrigerado é variável entre garanhões e laboratórios (KATILA, 1997), apesar da difusão do seu uso, há considerável variação em suas taxas de fertilidade além do que à medida que o tempo de armazenamento aumenta, a fertilidade do sêmen diminui (PICKETT, 1995). O sucesso da utilização do sêmen equino refrigerado depende de fatores que se confundem, tais como: taxa de resfriamento, temperatura de armazenamento, composição do meio diluente, dose inseminante, número de inseminações, qualidade do sêmen a fresco, manuseio do sêmen, entre outras. (BATELIER et al., 2001).

A preservação da viabilidade espermática através da refrigeração oferece muitas vantagens aos criadores de cavalos. Entre elas está o estresse causado pelo deslocamento do garanhão até a fêmea em cio, sendo que na maioria das vezes o deslocamento de um garanhão do seu habitat pode ocasionar queda da qualidade espermática, a qual terá como tempo de recuperação um período que varia de 90 a 120 dias para o restabelecimento da espermatogênese normal (MELO et al., 2005a). Para que essa biotecnologia tenha sucesso, o sêmen deve ser processado de forma adequada permitindo assim a garantia de sua preservação por alguns dias (JASKO, 1994). 
SILVA, R.P. et al. Avaliação de dois diluentes de refrigeração e o efeito da presença do plasma seminal sobre a viabilidade do sêmen equino refrigerado. PUBVET, Londrina, V. 5, N. 20, Ed. 167, Art. 1126, 2011.

\subsection{Efeito do Plasma Seminal Sobre a Viabilidade do Sêmen Equino Refrigerado}

O sêmen é constituído de células espermáticas e do plasma seminal, o qual contém substâncias benéficas aos espermatozóides. O plasma seminal equino, porção fluída do ejaculado, no qual os espermatozóides estão presentes (GARNER \& HAFEZ, 2004), é composto pelas secreções do epidídimo, ampola do canal deferente, próstata, vesículas seminais e glândulas bulbo uretrais (VARNER et al., 1987). Este contém fatores estimulantes da motilidade espermática que podem ser divididos em dois grandes grupos. Um deles seria constituído por fatores de ativação catalítica, como certos íons, nucleotídeos e ativadores específicos, provavelmente de origem protéica, encontrados nas diversas glândulas acessórias, principalmente na próstata. 0 outro grupo seria formado por nutrientes que fornecem a energia metabólica exigida para motilidade e a sobrevivência dos espermatozóides (MANN \& LUTWAK-MANN, 1981). Além disso, o plasma seminal é importante no aumento do volume do ejaculado, o que provavelmente permite uma distribuição melhor dos espermatozóides no útero da égua (AMANN \& GRAHAM, 1993). Porém, somente o plasma seminal não é o meio ideal para

refrigerar e armazenar os espermatozóides. Elevadas concentrações de plasma seminal são deletérias aos espermatozóides quando submetidos à refrigeração e armazenamento (BRINSKO et al., 2000).

Segundo TROEDSSON (1999), no plasma seminal existem substâncias moduladoras da resposta inflamatória uterina pós-cobertura, e estas auxiliam na limpeza uterina de éguas suscetíveis a endometrite pós-cobertura. Além disso, o plasma seminal contém ocitocina e prostaglandinas, que promovem a contração uterina visando ao transporte do gameta masculino até o local da fertilização (KATILA, 2001) e substâncias antioxidantes como a cisteína, ergotioneína e glutationa peroxidase, capazes de minimizar os efeitos da peroxidação lipídica (AMANN \& GRAHAM, 1993).

Apesar do importante papel do plasma seminal no transporte e fisiologia do gameta masculino, este parece não ser o meio ideal para a preservação dos 
SILVA, R.P. et al. Avaliação de dois diluentes de refrigeração e o efeito da presença do plasma seminal sobre a viabilidade do sêmen equino refrigerado. PUBVET, Londrina, V. 5, N. 20, Ed. 167, Art. 1126, 2011.

espermatozóides in vitro já que grandes proporções de plasma seminal acarretam redução da motilidade espermática durante um longo período de estocagem sob refrigeração, enquanto pequenas quantidades melhoram sua sobrevida (SQUIRES et al., 1999).

Para diminuir as concentrações de plasma seminal do ejaculado pode-se utilizar da centrifugação do sêmen, em baixa rotação, para não ser deletéria à sobrevivência dos espermatozóides (PICKET et al., 1975). Segundo KELLER (1988), altas forças por tempo superior a dez minutos causam danos a membrana plasmática.

Comumente o sêmen equino é submetido à centrifugação antes da criopreservação para diminuir os efeitos do plasma seminal na motilidade pósdescongelação. JASKO et al. (1991) demonstraram que a motilidade espermática do sêmen refrigerado equino pode ser melhorada após centrifugação seguida da remoção do plasma seminal. KELLER et al. (2001) observaram melhores porcentagens de motilidade total e progressiva nas amostras contendo $1,95 \%$ de plasma seminal, quando comparados com as contendo $17,78 \%$ mostrando, assim, o efeito deletério da elevada concentração do plasma seminal sobre os parâmetros espermáticos, e demonstrando que sua remoção é um procedimento apropriado e viável.

De acordo com JASKO et al. (1992) são necessários para manter a motilidade do sêmen refrigerado equino em torno de $5 \%$ de plasma seminal. Estes autores demonstraram que a remoção total do plasma seminal e ressuspensão dos espermatozóides em diluente de refrigeração resultou em significativa $(p<0,05)$ queda das características de movimento avaliadas por computador em amostras refrigeradas por 24 horas. Já a ressuspensão em meio diluente contendo de 5 a $20 \%$ de plasma seminal foi suficiente para manter a motilidade espermática por mais de 72 horas de refrigeração. Entretanto, segundo SCHMITT et al. (2003), as diferentes concentrações de plasma seminal $(0 \% ; 2,5 \% ; 5 \% ; 10 \%)$ no sêmen equino refrigerado por 72 horas não foram suficiente para influenciar na motilidade espermática, nem na 
SILVA, R.P. et al. Avaliação de dois diluentes de refrigeração e o efeito da presença do plasma seminal sobre a viabilidade do sêmen equino refrigerado. PUBVET, Londrina, V. 5, N. 20, Ed. 167, Art. 1126, 2011.

funcionalidade de membrana dos espermatozóides avaliada por fluorescência (coloração carboxifluoresceína/iodeto de propídeo).

A interação entre a membrana plasmática do espermatozóide e os componentes específicos do plasma seminal parece interferir na suscetibilidade da membrana aos prejuízos causados pelo estresse térmico (AURICH, 2005). Os resultados de KANKOFER et al. (2005) sugerem que, para uma maior atividade de algumas enzimas antioxidantes, certa quantidade de plasma seminal deve ser mantida no ejaculado no momento da sua diluição.

BRINSKO et al. (2000), constataram que a centrifugação e remoção de aproximadamente $88 \%$ do plasma seminal antes do armazenamento a $5^{\circ} \mathrm{C}$ por 24 e 48 horas resultou no aumento de motilidade espermática do sêmen de garanhões cujos ejaculados tinham baixa motilidade quando processados de forma convencional. Comprovando assim, que aparentemente o plasma seminal de alguns garanhões tem efeito tóxico na motilidade espermática, o que quando o sêmen é refrigerado fica mais evidente. Consequentemente, para utilização de garanhões que apresentam baixos índices de refrigeração, a centrifugação e remoção parcial do plasma seminal parece ser uma alternativa para melhorar os parâmetros espermáticos.

\subsection{Diluentes Para Refrigeração de Sêmen Equino}

Diluentes de sêmen são soluções compostas por antibióticos, tampões, proteínas, aminoácidos, açúcares, entre outros componentes, que são destinados a proteger os espermatozóides das condições desfavoráveis do ambiente e prolongar sua sobrevivência durante a refrigeração e o transporte, além de apresentarem como vantagem o aumento do volume da dose inseminante o que, consequentemente, auxilia tanto na análise do sêmen quanto no percurso dos espermatozóides no trato reprodutivo da fêmea (DARENIUS, 1998).

Uma característica importante dos diluentes utilizados na preservação do sêmen equino refrigerado é a capacidade de estabilizar as membranas espermáticas durante a fase de transição, momento no qual ocorrem as 
SILVA, R.P. et al. Avaliação de dois diluentes de refrigeração e o efeito da presença do plasma seminal sobre a viabilidade do sêmen equino refrigerado. PUBVET, Londrina, V. 5, N. 20, Ed. 167, Art. 1126, 2011.

maiores lesões celulares. Assim, para minimizar os danos causados pelo choque térmico uma variedade de substâncias pode ser adicionada ao meio diluidor (KENNEY et al., 1975).

O sucesso da inseminação artificial em equinos, como nas demais espécies de produção, depende da manutenção da viabilidade e fertilidade espermática durante a refrigeração e armazenamento (IJAZ \& DUCHARME, 1995). Empenhos para melhorar a conservação do sêmen refrigerado equino se concentram na alteração de diluentes bem como na adição de componentes específicos com intuito de manter a integridade de membrana, prevenir o estresse oxidativo e preservar a motilidade espermática (MELO, 2005). Diferentes antibióticos, tampões, açúcares e, mais recentemente, a adição de agentes indutores de funcionalidade da célula espermática estão sendo investigados a fim de se obter uma melhor preservação do ejaculado de garanhões com baixa qualidade seminal (NUNES et al., 2006).

Os crioprotetores extracelulares mais utilizados são à base de leite e/ou de gema de ovo. Estes são considerados práticos e eficientes na proteção do sêmen equino durante $o$ armazenamento antes da IA e rotineiramente são utilizados para diluição e armazenamento do sêmen refrigerado entre $4^{\circ} \mathrm{C}$ e $8^{\circ} \mathrm{C}$ (BATELLIER et al., 2001).

A gema de ovo confere proteção contra choque térmico aos espermatozóides, essa ação protetora deve-se às lipoproteínas de baixa densidade (AMANN \& GRAHAM, 1993), que permanecem firmemente ligadas aos espermatozóides (FOULKES, 1977). No entanto, a gema de ovo contém progesterona, o que poderia induzir uma capacitação espermática precoce, ocasionando assim redução da fertilidade (LIPAR et al., 1999), segundo CHENG et al., (1998) a ligação da progesterona exógena marcada ao receptor localizado na membrana plasmática do espermatozóide equino parece ser um importante passo na indução da reação acrossomal.

Apesar de não se conhecer o exato mecanismo de proteção do leite contra o choque térmico, provavelmente as proteínas do leite agem de modo similar às lipoproteínas da gema de ovo, estabilizando as membranas (AMANN 
SILVA, R.P. et al. Avaliação de dois diluentes de refrigeração e o efeito da presença do plasma seminal sobre a viabilidade do sêmen equino refrigerado. PUBVET, Londrina, V. 5, N. 20, Ed. 167, Art. 1126, 2011.

\& GRAHAM, 1993). BATELLIER et al. (2001) relataram que a proteção conferida pelos componentes do leite estaria relacionada aos seus efeitos antioxidantes. De acordo com BATELLIER et al. (1997) o leite é um fluído biológico com uma complexa composição, mais de 100.000 moléculas, e algumas como $\beta$-lactoglobulina são benéficas, enquanto outras, como alactoalbumina, são prejudiciais à sobrevivência dos espermatozóides.

CARVALHO et al. (2005) avaliaram a eficiência de diluentes, com ou sem a adição do aminoácido taurina, sobre a viabilidade espermática do sêmen equino, por 96 horas com avaliações em intervalos de 24 horas. Os resultados laboratoriais demonstraram que o diluente a base de leite desnatado - glicina, acrescido do aminoácido taurina, quando comparado ao diluente à base de leite desnatado - glicose, apresentou resultados superiores nos parâmetros espermáticos e na fertilidade.

GOULART et al. (2004), na tentativa de minimizar os efeitos provocados pelo estresse térmico causado pela refrigeração do sêmen equino, buscaram um indutor de funcionalidade, a pentoxifilina que, adicionada ao ejaculado diluído e refrigerado a $5^{\circ} \mathrm{C}$, melhorou os parâmetros espermáticos avaliados, relacionados à motilidade, provavelmente isso ocorreu por consequência do aumento da concentração intracelular de nucleotídeos cíclicos, em especial da adenina monofosfato cíclica (AMPc) e da guanosina monofosfato cíclica (GMPc).

A utilização de antibióticos nos meios de diluição de sêmen é recomendada com 0 intuito de diminuir o crescimento bacteriano no armazenamento do sêmen até o momento da IA. No entanto, estes não devem interferir na qualidade seminal ou mesmo impedir o estabelecimento da microflora vaginal, pois ocorrendo isso, poderia favorecer o crescimento de microrganismos patogênicos (DARENIUS, 1998).

Encontram-se disponíveis no mercado brasileiro os diluentes BotuSêmen ${ }^{\circledR}$ e Botu-Turbo ${ }^{\circledR}$, comercializados pela Biotech - Botucatu-SP; MaxSêmen ${ }^{\circledR}$ e Max-Sêmen Plus ${ }^{\circledR}$ distribuídos pela E.H.G. Agrofarma - Mogi MirimSP, e ainda o Equimix ${ }^{\circledR}$, comercializado pela Nutricell - Campinas-SP. As versões Turbo e Plus, segundo os fabricantes, são acrescidas de componentes 
SILVA, R.P. et al. Avaliação de dois diluentes de refrigeração e o efeito da presença do plasma seminal sobre a viabilidade do sêmen equino refrigerado. PUBVET, Londrina, V. 5, N. 20, Ed. 167, Art. 1126, 2011.

que aumentam a motilidade espermática e melhoram a sobrevida do sêmen de garanhões submetidos a refrigeração (NUNES, 2006).

\subsection{Parâmetros Espermáticos Para Avaliação de Sêmen: Motilidade Total, Motilidade Progressiva, Vigor Espermático e Integridade de Membrana Plasmática.}

Para preservação da célula espermática, deve-se promover, obrigatoriamente, a preservação de sua capacidade funcional, fecundante, o que, implica na manutenção da integridade celular espermática, a habilidade em penetração no ovócito e a competência para suportar o desenvolvimento embrionário (HARRISON et al., 1996).

Quando se trabalha com criopreservação de sêmen, o que se busca, impreterivelmente é uma excelente taxa de fertilidade. No entanto, para realização de testes de fertilidade, além de estes apresentarem custo elevado, se trabalhando com um número restrito de animais, há a desvantagem do teste apresentar baixa confiabilidade (TARDIF et al., 1999).

Análises in vitro possuem a vantagem de mostrar quais aspectos da função espermática foram prejudicados ou mantidos com a refrigeração, sendo isso um ponto bastante interessante de ser observado ao se buscar o aprimoramento de técnicas de preservação de sêmen. Várias técnicas in vitro têm sido descritas para a avaliação do sêmen, porém a combinação de diferentes métodos de avaliação fornece um resultado mais confiável do que um único teste quando se deseja prever a fertilidade in vivo (STRÖM, 1999).

A avaliação objetiva computacional oferece vantagens sobre o método subjetivo, uma vez que há possibilidade de avaliação de parâmetros da cinética espermática, tais como: velocidade de trajeto, velocidade progressiva, velocidade curvilínea, amplitude lateral de cabeça, frequência de batimentos de cauda, retilinearidade, linearidade, velocidade rápida, deslocamento lateral de cabeça, entre outras avaliações (ARRUDA, 2000). No entanto, por se tratar de uma técnica acessível nas avaliações realizadas no campo, não requerendo condições especiais para sua realização, a avaliação convencional (subjetiva) 
SILVA, R.P. et al. Avaliação de dois diluentes de refrigeração e o efeito da presença do plasma seminal sobre a viabilidade do sêmen equino refrigerado. PUBVET, Londrina, V. 5, N. 20, Ed. 167, Art. 1126, 2011.

com microscopia óptica é a mais rotineiramente utilizada para avaliação de reprodutores equídeos.

Segundo VIDAMENT (2005), as únicas características que apresentaram correlação com fertilidade para sêmen de equídeos são a motilidade e a velocidade rápida.

Outro aspecto favorável à utilização da avaliação subjetiva foi a alta correlação entre análise objetiva e subjetiva observada por KOLIBIANAKIS et al. (1992). Estes autores, em estudo com 114 amostras de sêmen, observaram alta correlação $(P<0,01)$ entre as avaliações feitas com a análise subjetiva e a computacional.

Embora possua correlação de baixa a média intensidade, com a fertilidade, por não avaliar todos os atributos que os espermatozóides devem possuir para a fecundação, dentre os testes laboratoriais, a avaliação da motilidade é comumente utilizada por ser relativamente simples e barata (SQUIRES et al., 1999).

A motilidade espermática é o parâmetro espermático mais utilizado na avaliação do sêmen, definida como a avaliação subjetiva do percentual de espermatozóides móveis (SEAGER \& FLETCHER, 1972). O exame é realizado em microscópio óptico com objetiva de 10 ou 40 vezes de aumento, observando-se uma gota de sêmen entre lâmina e lamínula previamente aquecidas, podendo ser avaliada imediatamente após a colheita ou após a refrigeração do sêmen (BARBOSA et al., 2005).

O percentual de motilidade espermática, particularmente a motilidade progressiva, é um bom indicativo de viabilidade espermática em equídeos (MOREL, 1999). Apesar de não necessariamente ser um indicador da capacidade fecundante, a motilidade espermática obrigatoriamente deve estar presente para que o espermatozóide possa fecundar (VOSS et al., 1981).

Segundo HAFEZ (1995), a motilidade dos espermatozóides é essencial para o processo de fertilização in vivo, uma vez que é necessário que essas células altamente especializadas se desloquem do meio uterino até o ovócito para sua fertilização. 
SILVA, R.P. et al. Avaliação de dois diluentes de refrigeração e o efeito da presença do plasma seminal sobre a viabilidade do sêmen equino refrigerado. PUBVET, Londrina, V. 5, N. 20, Ed. 167, Art. 1126, 2011.

Vigor é a intensidade de movimentação do espermatozóide individualmente. A avaliação normalmente é realizada em conjunto com a motilidade sendo definido como a qualidade do movimento exibido pelos espermatozóides móveis. A escala de avaliação varia de zero a cinco, em que zero representa células paradas e cinco, movimento vigoroso e de alta velocidade (BARBOSA et al., 2005).

Têm sido utilizados testes laboratoriais que avaliam a morfologia dos espermatozóides, a integridade estrutural da membrana plasmática por meio de colorações fluorescentes (ZÚCCARI, 1998), além daqueles que avaliam a integridade funcional, por exemplo, o teste hiposmótico (AURICH, 2005).

O teste hiposmótico foi desenvolvido para avaliar a atividade bioquímica da membrana plasmática. Em condições de hiposmolaridade, as trocas de fluidos realizadas pela membrana plasmática têm continuidade até que o equilíbrio osmótico seja atingido (ZÚCCARI, et al., 2009).

A membrana plasmática é responsável pela manutenção do equilíbrio osmótico celular, atuando como uma barreira entre os meios intra e extracelulares. Danos nesta estrutura, que é mais afetada pelo choque frio, podem levar a perda da homeostase com posterior morte da célula (AMANN \& GRAHAM, 1993). Devido ao influxo de líquido, a membrana plasmática se expande, e causa o aumento do volume da célula, especialmente na região da cauda, o que provoca enrolamento (ROTA et al., 2000).

Após atingir a maturidade, o espermatozóide, perde a maioria de suas organelas e a transição do DNA é cessada, sendo assim impossível sintetizar novos componentes da membrana plasmática. Assim, danos à mesma resultam em irreversível perda de sua função (EDDY et al., 1994). Com isso, a integridade da membrana plasmática é fundamental para a sobrevivência do espermatozóide no trato genital da fêmea e para a manutenção de sua capacidade fecundante (PARKS et al., 1992).

O teste hiposmótico $(\mathrm{HO})$ na avaliação da integridade funcional da membrana plasmática trata-se de um teste complementar importante na avaliação in vitro do sêmen criopreservado, uma vez que tanto a congelação 
quanto o resfriamento podem levar a efeitos deletérios sobre a membrana plasmática (MELO et al., 2005b).

Segundo MELO et al. (2005b), o teste hiposmótico adiciona informações ao exame convencional do sêmen e pode ser utilizado para comparar diferentes processos de preservação do sêmen equino.

Segundo NEILD et al. (2005), para aumentar a acurácia ao se predizer a fertilidade do garanhão antes deste ser utilizado como doador de sêmen durante a estação de monta deve ser utilizada um combinação de provas laboratoriais.

\section{MATERIAL E MÉTODOS}

O experimento foi realizado na Estação Experimental de Zootecnia do Instituto Federal Goiano - Campus Rio Verde, no período de agosto de 2007 a junho de 2008. Foram utilizados cinco garanhões mestiços com idade variando entre 3 a 7 anos, estes eram animais de trabalho na lida do campo, oriundos de propriedades da região. Submeteu-se cada reprodutor a um total de cinco colheitas de sêmen.

Durante o experimento, os animais eram mantidos em um piquete com pastagem de Brachiaria brizantha cv. Marandú próximo à Estação Experimental, com fornecimento de água ad libitum, e quatro kg de ração para equinos com $13 \%$ de proteína bruta.

As colheitas de sêmen foram realizadas através de vagina artificial, modelo Biotech, previamente montada composta por tubo rígido de PVC, com mucosa de látex revestida por mucosa plástica descartável, acoplada a um coletor isotérmico revestido por camisa sanitária para proteger o ejaculado da luminosidade excessiva e temperatura elevada, estando a temperatura da vagina artificial em torno de $45^{\circ} \mathrm{C}$. Para realização das colheitas de sêmen, para refrigeração do ejaculado em seis protocolos diferentes, utilizou-se como manequim uma fêmea em cio. 
SILVA, R.P. et al. Avaliação de dois diluentes de refrigeração e o efeito da presença do plasma seminal sobre a viabilidade do sêmen equino refrigerado. PUBVET, Londrina, V. 5, N. 20, Ed. 167, Art. 1126, 2011.

Logo após a colheita o ejaculado era enviado ao laboratório, onde foi rapidamente filtrado através de filtro de nylon, modelo nacional, para retirada da porção gel, em seguida eram realizadas as avaliações para viabilidade espermática do sêmen por meio de análises microscópicas em que colocava-se uma gota de sêmen entre lâmina e lamínula previamente aquecidas a $37^{\circ} \mathrm{C}$ e avaliava-se a porcentagem de motilidade total (MT\%) e progressiva (MP\%) dos espermatozóides, a intensidade do movimento dos espermatozóides, vigor, ( $V$ - 0 a 5), e integridade de membrana plasmática da amostra de sêmen, sendo que a integridade de membrana foi avaliada apenas com 24 horas de refrigerado.

Parte do ejaculado foi centrifugado a $600 \mathrm{~g}$ por 10 minutos, sem diluente, apenas para recuperação do plasma seminal, para ser utilizado em dois protocolos os quais foram testados. O restante do ejaculado dividiu-se em seis partes onde foram refrigerados de acordo com os seguintes protocolos: Protocolo I - Controle B - Não centrifugado diluído na proporção 2:1 (diluente:sêmen) com Botu-Sêmen ${ }^{\circledR}$; Protocolo II - Centrifugado por 10 minutos a $600 \mathrm{~g}$ e ressuspendido somente com Botu-Sêmen ${ }^{\circledR}$, sem plasma seminal; Protocolo III - Centrifugado por 10 minutos a $600 \mathrm{~g}$ e ressuspendido com $80 \%$ de Botu-Sêmen ${ }^{\circledR}$ e $20 \%$ de plasma seminal; Protocolo IV - Controle E - Não centrifugado diluído na proporção 2:1 (diluente:sêmen) com Equimix ${ }^{\circledR}$; Protocolo V - Centrifugado por 10 minutos a $600 \mathrm{~g}$ e ressuspendido somente com Equimix ${ }^{\circledR}$, sem plasma seminal; Protocolo VI - Centrifugado por 10 minutos a $600 \mathrm{~g}$ e ressuspendido com $80 \%$ de Equimix ${ }^{\circledR}$ e $20 \%$ de plasma seminal.

Logo após a diluição e homogeneização das amostras, momento T0, foram avaliados a MT\%, MP\% e V(0 a 5).

As amostras de sêmen dos seis protocolos testados foram armazenadas em tubos de centrífuga de $15 \mathrm{~mL}$, com tampa, os quais foram acondicionados em caixa de isopor contendo água a $25^{\circ} \mathrm{C}$. Esta caixa, contendo água e as amostras de sêmen, foi colocada, sem tampa, em geladeira a $5^{\circ} \mathrm{C}$. 
Após 24 (T24), 48 (T48) e 72 (T72) horas de refrigeração, retirou-se um $\mathrm{mL}$ de cada amostra, colocando-o em eppendorf previamente identificados com o protocolo testado. Estas amostras foram aquecidas por 10 minutos a $37^{\circ} \mathrm{C}$ e novamente avaliados a MT\%, MP\% e V (0 a 5), sendo que após 24 (T24) horas de refrigeração avaliou-se a integridade de membrana plasmática (\%), através de teste hiposmótico ( $\mathrm{HO})$.

As análises de $\mathrm{MT} \%, \mathrm{MP} \%$ e $\mathrm{V}(0$ a 5$)$ foram realizadas através de observação microscópica, colocando-se uma gota de sêmen entre lâmina e lamínula pré-aquecidas a $37^{\circ} \mathrm{C}$.

A porcentagem de espermatozóides com membrana plasmática íntegra foi avaliada através do teste hiposmótico $(\mathrm{H} 0)$, onde se colocou duas gotas de sêmen equino em eppendorf contendo água destilada pré-aquecida a $37^{\circ} \mathrm{C}$. Foi avaliada então a porcentagem de células espermáticas com membrana plasmática integra através da contagem de 100 células, onde a quantidade de células com membrana plasmática íntegra foi realizada através de avaliação de microscopia óptica, no aumento de 40 vezes.

Para análise dos dados foi utilizado esquema fatorial $6 \times 4$ (Protocolos de refrigeração x Tempo), com análise de variância comparada entre as médias dos grupos seguido do teste de Tukey. O nível de significância utilizado foi de $5 \%$ sendo o programa utilizado para as análises estatísticas o software SAS (2002).

\section{RESULTADOS E DISCUSSÃO}

Nas Tabelas 1, 2 e 3, são apresentadas as médias de MT, MP e Vigor, respectivamente, segundo os protocolos I, II, III, IV, V e VI das amostras de sêmen equino logo após a diluição antes da refrigeração (T0), com 24 (T24), 48 (T48) e 72 (T72) horas de refrigeração a $5^{\circ} \mathrm{C}$. 
SILVA, R.P. et al. Avaliação de dois diluentes de refrigeração e o efeito da presença do plasma seminal sobre a viabilidade do sêmen equino refrigerado. PUBVET, Londrina, V. 5, N. 20, Ed. 167, Art. 1126, 2011.

TABELA 1 - Médias referentes à porcentagem de motilidade total, segundo os protocolos avaliados, PI, PII, PIII, PIV, PV e PVI, logo após a diluição antes da refrigeração, com 24, 48 e 72 horas de refrigeração em geladeira a $5^{\circ} \mathrm{C}$.

\begin{tabular}{lccccc}
\hline \multirow{2}{*}{ Protocolos } & \multicolumn{4}{c}{ Tempos de refrigeração } & \multirow{2}{*}{ Média } \\
\cline { 2 - 5 } & T0 & T24 & T48 & T72 & \\
\hline PI & 85,0 & 60,0 & 35,3 & 9,10 & $47,3 \mathrm{~A}$ \\
PII & 82,6 & 59,4 & 45,8 & 22,16 & $52,5 \mathrm{~A}$ \\
PIII & 82,0 & 63,8 & 37,8 & 13,64 & $49,3 \mathrm{~A}$ \\
PIV & 85,0 & 58,8 & 39,6 & 15,48 & $49,7 \mathrm{~A}$ \\
PV & 81,4 & 60,2 & 45,2 & 26,28 & $53,3 \mathrm{~A}$ \\
PVI & 82,3 & 60,8 & 47,0 & 15,40 & $51,1 \mathrm{~A}$ \\
Média & $82,9 a$ & $60,5 \mathrm{~b}$ & $41,0 \mathrm{c}$ & $17,0 \mathrm{~d}$ & \\
\hline
\end{tabular}

Fonte de variação

Protocolo $\quad 0,1204$

Tempo $\quad<0,001$

Prot.x temp. $\quad 0,1961$

C.V. $\quad 37,95$

*Médias seguidas por letras diferentes minúsculas na linha e maiúsculas na coluna diferem entre si pelo teste de Tukey a $5 \%$ de probabilidade.

Como observado nas Tabelas 1, 2, 3 e 4 não houve efeito da presença do plasma seminal sobre a viabilidade espermática nos parâmetros espermáticos avaliados (MT, MP, $\mathrm{V}$ e HO), tais resultados divergem dos encontrados por LOVE et al. (2005), os quais obtiveram melhor preservação da motilidade espermática e da integridade do DNA na ausência de plasma seminal quando o ejaculado foi diluído e refrigerado por 48 horas.

Os resultados deste estudo discordam do encontrado por JASKO et al. (1991), estes autores concluíram que a motilidade espermática do sêmen pode ser melhorada com a centrifugação seguida de remoção do plasma seminal, bem como de KELLER et al. (2001) os quais observaram melhores 
SILVA, R.P. et al. Avaliação de dois diluentes de refrigeração e o efeito da presença do plasma seminal sobre a viabilidade do sêmen equino refrigerado. PUBVET, Londrina, V. 5, N. 20, Ed. 167, Art. 1126, 2011.

porcentagens de motilidade total e progressiva nas amostras contendo 1,95\% de plasma seminal, quando comparados com as contendo $17,78 \%$ mostrando assim, o efeito deletério da elevada concentração do plasma seminal sobre os parâmetros espermáticos, demonstrando assim que sua remoção é um procedimento apropriado e viável.

TABELA 2 - Médias referentes à porcentagem de motilidade progressiva, segundo os protocolos avaliados, PI, PII, PIII, PIV, PV e PVI, logo após a diluição antes da refrigeração, com 24, 48 e 72 horas de refrigeração em geladeira a $5^{\circ} \mathrm{C}$.

\begin{tabular}{|c|c|c|c|c|c|}
\hline \multirow{2}{*}{ Protocolos } & \multicolumn{4}{|c|}{ Tempos de refrigeração } & \multirow{2}{*}{ Média } \\
\hline & TO & T24 & T48 & T72 & \\
\hline PI & 58,4 & 35,8 & 20,2 & 3,68 & $28,8 \mathrm{~A}$ \\
\hline PII & 58,2 & 38,2 & 28,4 & 9,88 & $33,7 \mathrm{~A}$ \\
\hline PIII & 57,8 & 41,8 & 21,8 & 5,32 & $31,7 \mathrm{~A}$ \\
\hline PIV & 57,0 & 38,8 & 22,0 & 6,04 & $31,0 \mathrm{~A}$ \\
\hline PV & 56,6 & 39,4 & 29,0 & 12,16 & $34,3 \mathrm{~A}$ \\
\hline PVI & 58,3 & 38,0 & 29,2 & 5,48 & $32,7 \mathrm{~A}$ \\
\hline Média & $57,53 a$ & $38,83 b$ & $24,64 c$ & $7,09 d$ & \\
\hline
\end{tabular}

Fonte de variação

\begin{tabular}{lc}
\hline Protocolo & 0,2161 \\
Tempo & $<0,001$ \\
Prot. X temp. & 0,7990 \\
\hline C.V. (\%) & 52,08
\end{tabular}

*Médias seguidas por letras diferentes minúsculas na linha e maiúsculas na coluna diferem entre si pelo teste de Tukey a $5 \%$ de probabilidade.

Como observa-se na Tabela 2, com 48 horas de refrigeração, os valores de motilidade progressiva estiveram abaixo de $40 \%$, o que é recomendado por DARENUIS (1998). Entretanto segundo SQUIRES et al. (1999), a motilidade possui correlação de baixa a média intensidade com a fertilidade, por não 
SILVA, R.P. et al. Avaliação de dois diluentes de refrigeração e o efeito da presença do plasma seminal sobre a viabilidade do sêmen equino refrigerado. PUBVET, Londrina, V. 5, N. 20, Ed. 167, Art. 1126, 2011.

avaliar todos os atributos que os espermatozóides devem possuir para a fecundação.

Não foi observada diferença estatística $(p>0,05)$, entre os protocolos testados em nenhum dos parâmetros de qualidade de sêmen avaliados (MT, MP e V), nos diferentes tempos de refrigeração testados. Resultados estes que diferem dos encontrados por SCHMITT (2003), que não observou influência da concentração de até $5 \%$ de plasma seminal e dos diluentes testados sobre os parâmetros espermáticos avaliados, a motilidade, a funcionalidade e a integridade de membrana plasmática dos espermatozóides.

Os resultados apresentados nas Tabelas 1,2 e 3 sugerem apenas diluição de forma convencional, como nos protocolos I e IV, por não demandarem de equipamento e um tempo maior para o processamento, entretanto BRINSKO et al. (2000), constataram que a centrifugação e preservação de aproximadamente $12 \%$ do plasma seminal antes do armazenamento a $5^{\circ} \mathrm{C}$ por 24 e 48 horas resultou no aumento de motilidade espermática do sêmen de garanhões cujos ejaculados tinham baixa motilidade quando processados de forma convencional.

Como pode-se observar na Tabela 3, não houve variação no vigor espermático das amostras de sêmen refrigerado nos diferentes protocolos avaliados, contendo $0 \%, 20 \%$ ou $100 \%$ do plasma seminal. Este resultado diverge do resultado de JASKO et al. (1992), ao concluírem que a centrifugação e remoção total do plasma seminal, resultou em uma redução significante da viabilidade espermática, sugerindo que uma pequena concentração de plasma seminal seja essencial para a manutenção da capacidade de fertilização, dos espermatozóides oriundos de sêmen equino refrigerado.

Os resultados deste trabalho foram diferentes dos encontrados por MACEDO (2005), o qual comparou amostras centrifugadas e não centrifugadas, refrigeradas e verificou que após 72 horas a $5^{\circ} \mathrm{C}$, os parâmetros espermáticos do sêmen centrifugado foram superiores $(p<0,05)$ as amostras não centrifugadas. 
SILVA, R.P. et al. Avaliação de dois diluentes de refrigeração e o efeito da presença do plasma seminal sobre a viabilidade do sêmen equino refrigerado. PUBVET, Londrina, V. 5, N. 20, Ed. 167, Art. 1126, 2011.

TABELA 3 - Médias referentes à porcentagem de Vigor espermático, segundo os protocolos avaliados, PI, PII, PIII, PIV, PV e PVI, logo após a diluição antes da refrigeração, com 24, 48 e 72 horas de refrigeração em geladeira a $5^{\circ} \mathrm{C}$.

\begin{tabular}{|c|c|c|c|c|c|}
\hline \multirow{2}{*}{ Protocolos } & \multicolumn{4}{|c|}{ Tempos de refrigeração } & \multirow{2}{*}{ Média } \\
\hline & TO & T24 & T48 & T72 & \\
\hline PI & 3,60 & 2,28 & 1,48 & 0,28 & $1,9 \mathrm{~A}$ \\
\hline PII & 3,60 & 2,20 & 1,52 & 0,88 & $2,0 \mathrm{~A}$ \\
\hline PIII & 3,64 & 2,60 & 1,56 & 0,56 & $2,1 \mathrm{~A}$ \\
\hline PIV & 3,72 & 2,64 & 1,72 & 0,72 & $2,2 \mathrm{~A}$ \\
\hline PV & 3,68 & 2,32 & 1,80 & 1,20 & $2,2 \mathrm{~A}$ \\
\hline PVI & 3,75 & 2,60 & 1,96 & 0,64 & $2,2 \mathrm{~A}$ \\
\hline Média & $3,65 a$ & $2,44 b$ & $1,64 \mathrm{c}$ & $0,71 d$ & \\
\hline
\end{tabular}

\section{Fonte de Variação}

\begin{tabular}{lc}
\hline Protocolo & 0,0551 \\
Tempo & $<0,0001$ \\
Prot. $x$ temp. & 0,5358
\end{tabular}

C.V. (\%) $\quad 46,77$

*Médias seguidas por letras diferentes minúsculas na linha e maiúsculas na coluna diferem entre si pelo teste de Tukey a $5 \%$ de probabilidade.

$\mathrm{Na}$ Tabela 4 são apresentadas as médias referentes ao teste de integridade de membrana plasmática ( $\mathrm{HO})$ das amostras de sêmen equino com 24 horas de refrigeração segundo os seis protocolos avaliados, nota-se que não houve efeito significativo da presença do plasma seminal sobre a viabilidade espermática avaliada através de HO (\%) bem como MT (\%), MP (\%) e V (0 a 5).

Os resultados observados na Tabela 4 assemelham aos encontrados por SCHMITT et al. (2003), quando concluíram que diferentes concentrações de plasma seminal $(0 \% ; 2,5 \% ; 5 \% ; 10 \%)$ no sêmen equino refrigerado por 72 horas não foram suficientes para influenciar na motilidade espermática, nem 
SILVA, R.P. et al. Avaliação de dois diluentes de refrigeração e o efeito da presença do plasma seminal sobre a viabilidade do sêmen equino refrigerado. PUBVET, Londrina, V. 5, N. 20, Ed. 167, Art. 1126, 2011.

na funcionalidade de membrana dos espermatozóides avaliada por fluorescência.

TABELA 4 - Médias referentes ao teste de integridade de membrana (H0) das amostras de sêmen equino com 24 horas de refrigeração segundo os protocolos avaliados, PI, PII, PIII, PIV, PV e PVI.

\begin{tabular}{|c|c|}
\hline $\begin{array}{c}\text { Protocolos de refrigeração de } \\
\text { sêmen }\end{array}$ & Médias HO \\
\hline Protocolo I & $35,9 \mathrm{~A}$ \\
\hline Protocolo II & $38,6 \mathrm{~A}$ \\
\hline Protocolo III & $31,1 \mathrm{~A}$ \\
\hline Protocolo IV & $32,5 \mathrm{~A}$ \\
\hline Protocolo V & $34,0 \mathrm{~A}$ \\
\hline Protocolo VI & $34,3 \mathrm{~A}$ \\
\hline
\end{tabular}

Fonte de Variação

Protocolo 0.2716

C.V. (\%) 33.04

*Médias seguidas por letras iguais maiúsculas na coluna não diferem entre si pelo teste de Tukey a $5 \%$ de probabilidade.

Nota-se nas Tabelas 1, 2, 3 e 4 que a presença de plasma seminal equino em diferentes proporções, $0 \%, 20 \%$, e $100 \%$, não influenciou nos parâmetros espermáticos avaliados, o que contradiz aos resultados de SQUIRES et al. (1999), que concluíram que apesar do plasma seminal possuir importante papel no transporte e fisiologia do gameta masculino, grandes proporções do plasma no ejaculado acarreta redução da motilidade espermática durante um longo período de estocagem sob refrigeração, enquanto pequenas quantidades melhoram sua sobrevida.

Como observa-se nas Tabelas 1, 2 e 3, houve significativa redução na viabilidade espermática com o passar do tempo de refrigeração, o mesmo foi observado por NUNES (2006), que avaliando diferentes concentrações 
SILVA, R.P. et al. Avaliação de dois diluentes de refrigeração e o efeito da presença do plasma seminal sobre a viabilidade do sêmen equino refrigerado. PUBVET, Londrina, V. 5, N. 20, Ed. 167, Art. 1126, 2011.

espermáticas, observou maiores valores medianos $(p<0,05)$ da variável motilidade progressiva (\%) no momento pré-refrigeração quando comparados àqueles dos quatro tratamentos as 24 e 48 horas de refrigeração. O que pode ser explicado pelos danos promovidos durante o resfriamento, decorrentes de danos estruturais diretos, como a ruptura das membranas ou indiretos, por alterações das funções celulares (SQUIRES et al., 1999).

Os resultados obtidos no presente estudo, sugerem que apesar da centrifugação ser uma técnica bastante difundida e utilizada na refrigeração de sêmen equino, não há a necessidade da retirada do plasma seminal, uma vez que a centrifugação requer tempo, mão-de-obra qualificada, equipamentos específicos como centrífuga e tubos, o que demanda certo custo.

\section{CONCLUSÃO}

Não houve efeito dos diluentes testados (Botu-Sêmen ${ }^{\circledR}$ e Equimix ${ }^{\circledR}$ ) e da presença do plasma seminal sobre os parâmetros espermáticos avaliados (MT, MP, V e HO) segundo os protocolos avaliados, PI, PII, PIII, PIV, PV e PVI, logo após a diluição antes da refrigeração, com 24, 48 e 72 horas de refrigeração em geladeira a $5^{\circ} \mathrm{C}$., no sêmen equino refrigerado a $5^{\circ} \mathrm{C}$ por até 72 horas.

\section{REFERÊNCIAS BIBLIOGRÁFICAS}

AMANN, R. P., GRAHAM, J. K. Spermatozoal function. In : McKinnon A. O. ; VOSS, J. L. Equine reproduction. 1Ed. Philadelphia : Lea \& Febiger, 1993. Cap 80, p.715-745.

ARRUDA RP. Avaliação dos efeitos de diluidores e crioprotetores para o espermatozóide equino pelo uso de microscopia de epifluorescência, citometria de fluxo, análises computadorizadas da motilidade (CASA) e da morfometria (ASMA). 2000. 120f. Tese (Tese de Livre Docência em Reprodução Animal) - Universidade de São Paulo, Faculdade de Medicina Veterinária e Zootecnia, São Paulo, 2000.

AURICH C. Factors affecting the plasma membrane function of cooled-stored stallion spermatozoa. Animal Reproduction Science, v.89, p.65-75, 2005.

BARBOSA, R. T., MACHADO, R., BERGAMASCHI, M. A. C. M. A importância do exame andrológico em bovinos. EMBRAPA. Circular técnica 41 p.65. ISSN 1516-4111X. São Carlos, SP Dezembro, 2005 
BATELLIER, F., MAGISTRINI, M., FAUQUANT, J., PALMER, E. Effect of milk fractions on survival of equine spermatozoa. Theriogenology 48, 391-410, 1997.

BATTELIER, F., VIDAMENT, M., FAUQUANT, J., DUCHAMP, G., ARNAUD, G., YVON, J.M., MAGISTRINI, M. Advances in cooled sêmen technology. Animal Reproduction Science, v.68, p.181-90, 2001.

BRISKO, S.P., CROCKETT, E.C., SQUIRES, E.L. Effect of centrifugation and partial removal of seminal plasma on equine spermatozoal motility after cooling and storage. Theriogenology, v.54, p.129-136, 2000.

CARVALHO, G.A.; ZAHN, F.S.; MELO, C.M.; ALVARENGA, M.A.; DELL'AQUA JR., J.A.; PAPA, F.O. Effects of different extenders on sperm parameters and fertility of equine colled semen. Animal Reproduction Science, v. 89, p.275-277, 2005.

CHENG F.P., GADELLA B.M., VOORHOUT W.F., FAZELI A., BEVERS M.M., COLENBRANDER B. Progesterone induced acrossome reaction in stallion spermatozoa is mediated by a plasma membrane progesterone receptor. Biology Reproduction, v.59, p.733-742, 1998.

DARENIUS, A. Experiences with chilled, transported equine semen. In: STALLION REPRODUCTION SYMPOSIUM, 1998, Society for Theriogenology - American Association DNA integrity. Theriogenology, v63, p.1584-1591, 2005.

EDDY, E. M., O'BRIEN, D. A. The spermatozoon. In: KNOBIL, E.; NEILL, J.D. The Phisiology of Reproduction. New York: Raven Press, 1994. p.29-77.

FOULKES JA. The separation of lipoproteins from egg yolks and their effect on the motility and integrity of bovine spermatozoa. Journal of Reproduction and Fertility, v.49, p.277-284, 1977

GARNER D. L., HAFEZ E. S. E. Espermatozóide e plasma seminal. In: Hafez ESE. Reprodução animal. 7. ed. Barueri: Manole, 2004. p.97-110.

GOULART, H. M.; SILVA, A. E. D. F.; MCMANUS, C.; PAPA, F. O. Efeitos da pentoxifilina sobre a viabilidade in vitro dos espermatozóides de equinos, após o resfriamento a $5^{\circ} \mathrm{C}$. Revista Brasileira de Zootecnia, v.33, n.1, p. 112-122, 2004.

HAFEZ, E.S.E. Reprodução animal, 6.ed., Manole Ltda: São Paulo, 1995.

HARRISON RAP, ASWORTH PJC, MILLER NGA. Assessment of sperm function under fertilizing conditions. Reproduction in Domestic Animals, v.31, p.25-30, 1996.

IJAZ, A.; DUCHARME, R. Effect of various extenders and taurine on survival of stallion sperm cooled to $5^{\circ} \mathrm{C}$. Theriogenology, v.44, p.1039-1050, 1995.

JASKO, D.J. Procedures for cooling and freezing of equine semen. ARS Veterinaria, v.10, n.2, p.156-165, 1994.

JASKO, D.J., HATHAWAY, J.A., SCHALTENBRAND, V.L., SIMPER, W.D., SQUIRES, E.L. Effect of plasma seminal and egg yolk on motion characteristics of cooled stallion spermatozoa. Theriogenology, v.37, p.1241-52, 1992.

JASKO, D.J.; MORAN, D.M.; FARLIN, M.E.; SQUIRES, E.L. Effect of seminal plasma dilution or removal on spermatozoal motion characteristics of cooled stallion semen. Theriogenology, v.35, p.1059-1068, 1991. 
JUNIOR, P.G. Estudo do complexo do agronegócio do cavalo no Brasil. Centro de estudos avançados em economia aplicada da ESALQ, Confederação da Agricultura e Pecuária do Brasil, 68 p. 2004.

KANKOFER M, KOLM G, AURICH J, AURICH C. Activity of glutathione peroxidase, superoxide dismutase and catalase and lipid peroxidation intensity in stallion semen during storage at $5^{\circ} \mathrm{C}$. Theriogenology, v.63, p.1354- 1365, 2005.

KATILA T. Sperm-uterine interactions: a review. Animal Reproduction Science, v.68, p.267$272,2001$.

KATILA, T. Procedures for handling fresh stallion semen. Theriogenology, v. 48, p.1217$1227,1997$.

KELLER, A. Efeito de dois métodos de remoção do plasma seminal, de três diluentes e do tempo de armazenamento sobre algumas características espermáticas dos equinos. Dissertação (Mestrado em Ciências Veterinárias), Faculdade de Veterinária, UFRGS. 1988.

KELLER, A.; MALSCHITZKY, E.; HÖTT, A.; VIEIRA, M.J., MATTOS, R.; GREGORY, R.M.; MATTOS, R.C. Effect of method of seminal plasma removal, extender and length of storage on motility and fertility of equine semen. In: International Symposium On Stallion Reproduction, 3., 2001, Colorado. Proceedings..., Colorado, 2001. p.318-319.

KENNEY RM, BERGMAN RV, COOPER WL. Minimal contamination techniques and preliminary findings. American Association of Equine Practitioners, v.21, p.327-336, 1975.

KOLIBIANAKIS EM, TARLATZIS BC, BONTIS J, PAPADIMAS J, SPANOS E, MANTALENAKIS S. Evaluation of Hamilton-Thorn automated semen analysis system. Arch Androl, v.28, p.213222, 1992.

LIPAR JL, KETTERSON ED, NOLAN VJR, CASTO JM. Egg yolk layers vary in the concentration of steroid hormones in two avian species. Gen Comp Endocrinol, v.115, p.220-227, 1999.

LOVE, C.C., BRINSKO, S.P., RIGBY, S.L., THOMPSON, J.A., BLANCHERD, T.L., VARNER, D.D. Relationship of seminal plasma level and extender type to sperm motility and extender type to sperm motility and DNA integrity. Theriogenology, v.63, p.1584-1591, 2005.

MACEDO, L.P. Efeito de diferentes diluentes e antibióticos sobre a longevidade e fertilidade do sêmen equino refrigerado a $5^{\circ} \mathrm{C}$. Botucatu, 2005. 80p. Dissertação (Mestrado) - Faculdade de Medicina Veterinária e Zootecnia - Universidade Estadual Paulista "Júlio Mesquita Filho".

MANN, T.; LUTWAK-MANN, C. Storage of semen for artificial insemination. In: MANN, T.; LUTWAK-MANN, C. Male reproduction and semen. New York, Springer Verlag, p. 23-28, 1981.

MELO, C.M. Efeito do armazenamento por 24 horas em diferentes sistemas de refrigeração sobre a viabilidade e fertilidade de sêmen congelado equino. Botucatu, 2005. 101p. Dissertação (Mestrado) - Faculdade de Medicina Veterinária e Zootecnia - Universidade Estadual Paulista "Júlio Mesquita Filho".

MELO, M. I. V., HENRY, M., BECKER, A.R.C.L. Teste hiposmótico para avaliação da viabilidade do sêmen equino resfriado com diferentes diluidores. Arquivo Brasileiro de Medicina Veterinária e Zootecnia, v.57, n.6, p.757-763, 2005a. 
MELO, C. M., ZAHN, F.S., MARTIN, I., ALBERTI, K., ORLANDI, C., SIQUEIRA FILHO, E.R., DELL AQUA Jr., J.A., ALVARENGA, M.A., PAPA, F.O. Effect of cooling stallion semen for $24 \mathrm{~h}$ before freezing on fertility rates. Animal Reproduction Science, v.89, p.250-52, 2005b.

MOREL D. M. C. G. Equine artificial insemination. Wallingford, Oxon: CAB International.1999. 406p.

NEILD DN, GADELLA BM, AGÜERO A, STOUT TAE, COLENBRANDER, B. Capacitation, acrosome unction and chromatin structure in stallion sperm. Animal Reproduction Science, v.89, p.47-56, 2005.

NUNES, D. B., Container (CP) para refrigeração e preservação do sêmen equino. Campo Grande MS, 2006. 68p. Dissertação (Mestrado) - Universidade Federal de Mato Grosso do Sul.

NUNES, D.B., ZÚCCARI, C. E. S. N., SILVA, E. V. C. Fatores relacionados ao sucesso da inseminação artificial de éguas com sêmen refrigerado. Revista Brasileira de Reprodução Animal, Belo Horizonte, v.30, n.1/2, p.42-56, 2006. of Equine Practitioners. Proceedings...1998, p.60-70.

PARKS, J. E.; GRAHAM, J. K. Effects of cryopreservation procedures on sperm membranes. Theriogenology, Nova York, v.38, p.209-222, 1992.

PICKETT, B.W. The Stallion: Retrospective analysis and opinions. Biology Reproduction (Mono1), p.547-64, 1995.

PICKETT, B. W.; SULLIVAN, J. J.; BYERS, W. W.; PACE, M. M.; REMMENGA, E. E. Effect of centrifugation and seminal plasma on motility and fertility of stallion and bull spermatozoa. Fertile Steril. Vol. 26 (2): 167-174, 1975;

PIMENTEL, C.A.; CARNEIRO, G.F. Biotécnicas aplicadas à reprodução de equinos. In: GONÇALVES, P.B.D.; FIGUEIREDO, J.R.; FREITAS, V.J.F. Biotécnicas Aplicadas à Reprodução Animal. 2aed. São Paulo: Editora Roca. p.145-159. 2008.

ROTA, A., PENZO, N., VICENTI, L., MANTOVANI, R. Hypoosmotic swelling test (HOS) as a screening assay for testing in vitro fertility of bovine spermatozoa. Theriogenology, v.53, p.1415-1420, 2000.

SAS. SAS /SATS User's Guide. Versão 9.1 Cary: SAS Institute, 2002.

SCHMITT, F. L. A concentração, a composição e a qualidade do plasma seminal na preservação do sêmen equino a $+4^{\circ} \mathrm{C}$. Porto Alegre, 2003. 84p. Dissertação de Mestrado no 339. Faculdade de Veterinária - Universidade Federal Rio Grande do Sul

SCHMITT, F. L.; JOBIM, M. I. M.; OBERST, E. R.; MALSCHITZKY, E.; GREGORY, R. M.; MATTOS, R. C. A concentração de plasma seminal e o diluente afetam as características espermáticas do sêmen equino resfriado. Revista Brasileira de Reprodução Animal, v.27, n.3, p.334-336, 2003.

SEAGER SWJ, FLETCHER WS. Progress on the use of frozen semen in the dog. Veterinary Record, v.92, p.6-10, 1972. 
SQUIRES EL, PICKETT BW, GRAHAM JK, VANDERWALL DK, MCCUE PM, BRUEMMER, JE. Cooled and frozen stallion semen. Fort Collins: Animal Reproduction and Biotechnology Laboratory, 1999 p.1-38.

STRÖM B. In vitro characterization of cryopreserved canine spermatozoa. 1999. 104f. Thesis (Doctorat) - Swedish University of Agricultural Sciences, Uppsala, 1999.

TARDIF S, LAFOREST JP, CORMIER N, BAILEY JL. The importance of porcine sperm parameters on fertility in vivo. Theriogenology, v.52, p.447-459, 1999.

TROEDSSON MH. Uterine clearance and resistance to persistent endometritis in the mare. Theriogenology, v.52, p.461-471, 1999

VARNER, D. D.; BLANCHARD, T. L.; LOVE C. L.; GARCIA, M. C.; KENNEY, R. M. Effects of semen fractionation and dilution ratio on equine spermatozoal motility parameters. Theriogenology, v. 28, n. 5, p. 709-723, 1987.

VIDAMENT M. French field results (1985-2005) on factors affecting fertility of frozen stallion semen. Animal Reproduction Science, v. 89, p.115-136, 2005.

VIDAMENT, M.; DUPERE, A.M.; JULIENNE, P.; EVAIN, A.; NOUE, P.; PALMER, E. Equine frozen semen: freezability and fertility field results. Theriogenology 48, 907-917, 1997.

VOOS JL, PICKETT BW, SQUIRES EL. Stallion spermatozoaal morphology and motility and their relationship to fertility. Journal of the American Veterinary Medical Association, v.178, p.287-289, 1981.

ZÚCCARI C. E. S. N. Efeito da criopreservação sobre a integridade estrutural da célula espermática equina. 1998. 121f. Tese (Doutorado em Medicina Veterinária) Universidade Estadual Júlio de Mesquita Filho (UNES), Faculdade de Medicina Veterinária e Zootecnia, Botucatu, SP, 1998.

ZÚCCARI, C. E. S. N.; LEITE, P. A.; PASSOS, T. S., CARRIJO, P. R; KIEFER, C. Correlação entre métodos de avaliação da integridade da membrana plasmática do espermatozóide bovino criopreservado. Revista Brasileira de Saúde e Produção Animal, v.10, n.3, p 678-684 jul/set, 2009. 